\title{
Temperament and Character Traits in Bipolar "I" Inpatients with and without Substance Abuse
}

\author{
Azadeh Kheradmand ${ }^{1 *}$ Yousef Semnani ${ }^{1}$ \\ ${ }^{1}$ Shahid Beheshti Medical University, Tehran, Iran \\ *Corresponding author: Azadeh Kheradmand: azad_wave@yahoo.com
}

\section{Abstract:}

Citation: Semnani Y., Kheradman dA.. (2019) Temperament and Character Traits in Bipolar "I" Inpatients with and without Substance Abuse. Open Science Journal 4(1)

Received: $22^{\text {nd }}$ October 2018

Accepted: $23^{\text {th }}$ March 2019

Published: $16^{\text {th }}$ April 2019

Copyright: (C) 2019 This is an open access article under the terms of the Creative Commons Attribution License, which permits unrestricted use, distribution, and reproduction in any medium, provided the original author and source are credited.

Funding: The author(s) received no specific funding for this work

Competing Interests: The author have declared that no competing interests exists.

Background: Bipolar disorder, a serious mental illness, affects a large number of people. They showed some differences in temperament and character traits in compared with healthy population. Moreover, they are prone to substance abuse. The aim of the study is comparing Temperament and Character traits in Bipolar "I" inpatients with and without substance abuse. Methods: In this Descriptive Cross-Sectional study, we recruited 228 patients with the diagnosis of bipolar I disorder by SCID-I. Patients' temperament and character traits were assessed by Temperament and Character Inventory (TCI) questionnaire.

Results: Novelty seeking showed significantly differences between the groups with and without substance abuse or dependency. Logistic regression model showed that noveltyseeking score significantly correlated with substance abuse inpatient with bipolar disorder.

Conclusion: Our findings indicated that novelty seeking is a major risk factor for substance abusing in bipolar patients

Keywords: Bipolar I disorder, Substance abuse, personality 


\section{Introduction}

Bipolar disorder is a common mood disorder with recurrent manic and depressive symptoms. It has a lifetime prevalence of 0.1 to $7.5 \%(2)$, which presents as two major clinical subtypes. Bipolar I disorder involves periods of severe mood episodes from mania to depression. Bipolar II disorder is a milder form involving episodes of hypomania that alternate with periods of major depression. (1).

These manic or depressive episodes can be interspersed by relatively normal mood periods (3). Bipolar patients often have other psychiatric comorbidities with a prevalence rate of up to $50 \%-70 \%$ (23).

Personality disorder and Substance related disorder (SRD) are also common in these patient (23). Personality disorders has been considered a predisposing factor or a behavioral marker for bipolar disorder with familial or genetic links (19). Cloninger has devised a dimensional psychobiologic model that assess two major personality components including character and temperament. Temperament and character are usually used synonymously, although these terms reflect different traits. Temperament is an inherent feature that do not change during life span, limbic system has its regulatory control. but, Character refers to the learned attributes that Hippocampus and neurocortex are regions involved in regulation (19). The temperament involves four dimensions including novelty seeking, harm avoidance, reward dependence and persistence. The character consists of self-directedness, cooperativeness, and self-transcendence (6).

The studies reported that Bipolar patients have a significantly higher harm avoidance than healthy individuals, but lower persistence, self-directedness, reward dependency, self-transcendence, and cooperativeness scores (4). Strakowski et al. found a link between high novelty seeking and poor prognosis in patients with bipolar disorder using tridimensional personality questionnaire (TPQ) (25). Other studies have found higher scores on novelty seeking, harm avoidance, reward dependence and lower scores in persistence and selfdirectedness in bipolar patients compared to healthy individuals. The high scores in harm avoidance were associated with early onset of disease and fewer suicide attempts. (26) Such findings show that patients with mood disorders exhibit different personality traits from healthy individuals. Importantly, the TCI (temperament and character inventory) by Cloninger Et al, has been shown to have very good reliability, internal consistency, and stability over time (27).

One of the important factor that play a role in preparation, acceleration or survival of substance abuser is personality. Personality disorders are common among substance abuser, clinical population and non-clinical population (7). Some study reports higher novelty seeking in substance abusers compared to healthy individuals (8-10). Gonzalo et al.,2007, confirm the relationship of Novelty seeking with Substance related disorder. Such association, however, has not been previously studied in patients with bipolar disorder. (19) This is in particular important as substance abuse can affect prognosis in patients with bipolar disorder with links to earlier onset, more severe presentation, increased rate of psychiatric admissions, higher suicide rate, and poor response to treatment (24). So paying attention to personality in these patients is important. 
To address the possible link between the substance, abuse and personality traits in bipolar patients, here we compared temperament and character traits in patients with bipolar I disorder in association with substance abuse.

\section{Material and Methods}

\section{Sample}

In this Descriptive Cross-Sectional study, 228 patients with bipolar I disorder were recruited from the psychiatric wards in Imam Hossein and Taleghani hospitals. Inclusion criteria were patients with basic education and age of above 18 whom confirmed with bipolar I by SCID-I, remission from acute-phase of illness based on Young Mania Rating questionnaire. Patients who were not cooperative excluded from the study. The patients were divided into two groups based on history of substance abuse or dependency based on DSM IV_TR (except Tobacco use) at any time during their illness. The study protocol was approved by the ethics committee of the Beheshti University of Medical sciences and all patients signed an informed consent for enrollment.

\section{Measurement}

The temperament and character traits were assessed using the Temperament and Character Inventory (TCI). The TCI questionnaire is used for measuring personal characteristics caused by inheritance (temperament) or environment (character). TCI includes four temperament traits (Novelty seeking, Harm Avoidance, Reward dependence, persistence) and three character traits (Selfdirectedness, Cooperativeness, Self-transcendence). This questionnaire includes a total of 125 questions and each personality dimension is scored separately. The Farsi version of TCI has been validated for clinical use in Iran by Kaviani et al; 2005.

We used the Young Mania Rating Scale (YMRS) as a measure of bipolar manic symptoms. YMRS is composed of 11 questions and the score of 12 or below (from total of 60) is considered as the remission phase. The Farsi version of YMRS has been validated for clinical use in Iran.

The Structured Clinical Interview for DSM IV-TR Axis I Disorders (SCID-I) was also used to diagnosis Bipolar disorder, which is a flexible tool that made by first Et al., in a research by Sharifi Et al. (12) the confidence interval was good. (12)

\section{Statistical Analysis}

The data were analyzed by using SPSS 21.0. The patients were divided in two groups based on substance use or dependency in each group (sample size 114; power $90 \% ; \alpha=0.05)$. The average age, duration of illness, temperament and character scores were calculated for both groups. To compare two groups, t-test was used. The qualitative variable such as gender was compared between two groups using the chi square test. We determined the probability of substance 
abuse based on the temperament and character traits as predictors using logistic regression. This was done after assessing data for normality (kolmogorov smirnov). In all the analyses, $\mathrm{p}<0.05$ was defined as the level of significance.

\section{Results}

228 patients with confirmed bipolar I disorder were divided in two groups based on history of substance abuse or dependence during their illness (114 patients in each group). After excluding six patients with substance use and four patients without substance use due to incomplete TCI questionnaires, there were $108(49.5 \%)$ patients in the group 'with substance use' and 110 (50.5\%) patients in the group 'without substance use'. The demographic information of both groups are provided in Table 1. From all participants,117 patients were male $(53.7 \%), 101$ patients were female $(43.6 \%)$ which in "with substance use" group 83 persons were male $(76.97 \%)$ and 25 patients were female $(23.1 \%)$ and in "without substance use" group 34 patients were male. (30.9\%) and 76 patients were female (69.1\%). The range of participant ages was 18-66y with mean of 34.67 and SD 10.67 that the mean age of patients "with substance use" was 33.93, SD 9.83, and the mean age of patients "without substance use" was 35.40 with SD 11.79. The duration of illness was between $1 \mathrm{y}-52 \mathrm{y}$ with mean of 9.56 , SD 8.35 that mean duration in "with substance use" group was 8.35 and mean duration in "without substance use" group was 10.74. The sex distribution in each group was significantly different. $(\mathrm{P}<0.0001)$ Also, illness duration in both groups showed statistically significant differences $(\mathrm{P}<0.05)$ (Table1). Table 2 shows the average scores for character and temperament traits for both groups. The comparisons between both groups showed a significant difference between the novelty seeking scores.

Other traits were not significantly different between both groups. We used logistic regression to evaluating Novelty seeking impact on substance abuse in patients with bipolar disorder. Results showed that this model can predict substance abuse in bipolar patients (Table 3 ).

Table1. Demographic characteristics

\begin{tabular}{|c|c|c|c|c|}
\hline \multicolumn{2}{|c|}{ Variable } & \multicolumn{2}{|c|}{$\begin{array}{l}\text { Substance } \\
\text { dependency) }\end{array}$} & \multirow[t]{2}{*}{ P-Value } \\
\hline & & $\begin{array}{l}\text { Yes } \\
n=108\end{array}$ & $\begin{array}{l}\text { No } \\
n=110\end{array}$ & \\
\hline \multirow[t]{2}{*}{ Gender } & Male & $83(76.9 \%)$ & $34(30.9 \%)$ & \multirow[t]{2}{*}{$\mathrm{p}<0.0001$} \\
\hline & Female & $25(23.1 \%)$ & $76(69.1 \%)$ & \\
\hline \multicolumn{2}{|l|}{ Age } & $33.93 \pm 9.83$ & $35.40 \pm 11.79$ & NS \\
\hline \multicolumn{2}{|c|}{ Illness duration } & $8.35 \pm 6.35$ & $10.74 \pm 8.35$ & $\mathrm{P}<0.05$ \\
\hline
\end{tabular}


Table2. Comparison of temperament and character factors between the groups

\begin{tabular}{|c|c|c|c|c|}
\hline \multirow{2}{*}{ Factors } & \multicolumn{2}{|c|}{ Substance Abuse history } & \multirow{2}{*}{ df } & t \\
\cline { 2 - 4 } & Yes & No & & \\
\hline Self Transcends & $9.05 \pm 3.49$ & $8.93 \pm 3.44$ & 216 & -0.253 \\
\hline Self-Directedness & $11.63 \pm 4.66$ & $11.37 \pm 4.71$ & 216 & -0.404 \\
\hline Cooperativeness & $16.40 \pm 12.26$ & $17.89 \pm 20.45$ & 216 & 0.652 \\
\hline $\begin{array}{c}\text { Persistence } \\
\text { Reward }\end{array}$ & $2.98 \pm 1.43$ & $3.09 \pm 1.27$ & 216 & 0.599 \\
\hline Dependence & $8.51 \pm 2.02$ & $8.32 \pm 2.25$ & 216 & -0.659 \\
\hline Harm avoidance & $9.45 \pm 3.44$ & $9.34 \pm 4.38$ & 216 & -0.203 \\
\hline Novelty seeking & $9.74 \pm 3.29$ & $8.86 \pm 2.98$ & 216 & $-2 / 06^{*}$ \\
\hline
\end{tabular}

$* \mathrm{p}<0.05$

Table3. Logistic regression

\begin{tabular}{|l|l|l|l|}
\hline Variable & B & SEB & Odds Ratio \\
\hline Constant & $*-0.854$ & 0.433 & 0.426 \\
\hline Novelty seeking & $* 0.09$ & 0.044 & 1.094 \\
\hline
\end{tabular}

$* \mathrm{p}<05$

\section{Discussion}

Bipolar patients show differences in temperament and character traits compared to healthy individuals (4). These patients also have a higher rate of substance abuse (5). Moreover, has been showed that some temperament and character factors such as novelty seeking is different in substance abusers (8-10). These evidences make a hypothesis that there is a relation between temperament and character traits and substance abuse in bipolar disorders. Substance abuse is more prevalent in male gender than female (13). Traditional gender roles for male gender make different social behaviors compared with female. Social role of males makes them aggressive, active, expressive of anger, but without displaying sadness. In contrast traditional gender roles for female make them compliant, 
passive, and expressing sadness without showing anger (14). So these different behaviors make a different social reaction. Our findings also in line with previous study and showed significantly higher frequency of male gender among Bipolar substance users than bipolar patients without drug use. The duration of illness was significantly lower in bipolar patients with substance abuse. It seems that this issue related to the effect of substance abuse on onset age of bipolar disease. In order for substance abuse to impact the age of onset of bipolar disorder, it must begin prior to the onset of affective symptoms. Stephen et al in a study of bipolar patients with substance abuse found a high age of onset in the patients and concluded that mood episodes in these patients can be present in future followed by many years' exposure with drugs (15).

The major finding in our study was a significantly higher score of novelty seeking in bipolar patients with substance use, this finding was consistent with previous studies, that they have found high NS is responsible for a population whom tends to use substance in order to obtain new and exciting sensations. (19) Cloninger related the search for sensations with low levels of Dopamine, which could explain the abuse of substance that tends to increase the Dopaminergic activity and therefore compensates this deficit.(19) Novelty seeking is a predisposing factor for substance use, as Julia et al. 2016 have shown higher Novelty seeking in Bipolar patients with substance use compared with Schizophrenia, Depression with substance use and greater Novelty Seeking was related to a higher severity of addiction.(28)

Gonzalo et al.,2007 has represented high NS in bipolar patients with current and past substance use compared with Bipolar without history of substance use, confirm the relationship of NS with Substance related disorder. (19) In contrast with our study, Henry et al.,2001, they found no significant differences in NS among patients with bipolar and controls and concluded NS would not be associated with Bipolar but related to Substance related disorder that SRD exclusion in their study could be the cause of this difference with our study. (29)

At least Novelty seeking, a personality trait defined by an interest of impulsive responding in seeking of novel and rewarding stimuli, a psychobiological process involved in novelty seeking similar with those of substance abuse (22). So, novelty seeking theoretically is a marker for substance abuse proneness.

In our study, there is no significant differences between two group in other temperament and character traits such as P, HA and SD. High harm avoidance has been the most consistent finding across bipolar studies with controls and appears to be associated with the sub syndrome depression. (30) In our study, we reviewed bipolar community so HA has no significant differences between two groups.

Persistence is related to the ability to preserve despite frustration and fatigue, it is possible that bipolar patients with low $\mathrm{P}$ may have more difficulty in stopping substance use despite its adverse consequences. (31) In our study $\mathrm{P}$ has no significant differences between two group, but lower P in "with substance use" group needs attention.

$\mathrm{RD}$ has no significant differences between two group in this study, but higher RD in "with substance use" group along with dependency and sensitivity could be expected. 
Character traits are progressive and depend on the multiple experiences an individual has throughout life, therefore manifestation of Axis I such as SRD have adverse consequences on the development and expression of character traits. (31) In our study, despite no significant differences between two group, in "with substance use" group high ST, low CO have been shown.

At least, this study could be a prelude to designing future studies about genetics, outcome and treatment for patients with Bipolar with and without Substance related disorder, based on their personality traits.

\section{Conclusion}

Collectively, our findings indicated that novelty seeking is a major risk factor for substance abusing in bipolar patients. Regression models also showed that novelty seeking score can be used as a predictor of substance abuse in bipolar patients.

\section{References:}

1. Holder SD. Psychotic and Bipolar Disorders: Bipolar Disorder. FP essentials. 2017 Apr;455:30.

2. Basso LA, Argimon II, Arteche A. Systematic review of the prevalence of bipolar disorder and bipolar spectrum disorders in population-based studies. Trends in psychiatry and psychotherapy. 2013;35(2):99-105.

3. McCormick U, Murray B, McNew B. Diagnosis and treatment of patients with bipolar disorder: a review for advanced practice nurses. Journal of the American Association of Nurse Practitioners. 2015 Sep 1;27(9):530-42.

4. BORDBAR MR, Faridhosseini F, Kaviani H, Kazemian M, Samari AA, LOTFABADI PM. Temperament and character personality dimensions in patients with bipolar I disorder. Turk Psikiyatri Dergisi. 2014 Oct 1;25(3):149.

5. Cassidy F, Ahearn EP, Carroll BJ. Substance abuse in bipolar disorder. Bipolar disorders. 2001 Aug 1;3(4):181-8.

6. Sayın A, Kuruoğlu AÇ, Güleç MY, Aslan S. Relation of temperament and character properties with clinical presentation of bipolar disorder. Comprehensive psychiatry. 2007 Oct $31 ; 48(5): 446-51$.

7. Amirabadi B, Nikbakht M, Alibeygi N, Jalali M. Comparative personality traits of temperament and character, psychopathology, and onset age of smoking in predicting opiate dependence. International Journal of Applied Behavioral Sciences. 2016 Jan 20;2(1):35-40.

8. Etter JF. Smoking and Cloninger's temperament and character inventory. Nicotine \& Tobacco Research. 2010 Sep 1;12(9):919-26.

9. Milivojevic D, Milovanovic SD, Jovanovic M, Svrakic DM, Svrakic NM, Svrakic SM, Cloninger CR. Temperament and character modify risk of drug addiction and influence choice of drugs The American journal on addictions. 2012 Sep 1;21(5):462-7.

10. Schneider Jr R, Ottoni GL, Carvalho HW, Elisabetsky E, Lara DR. Temperament and character traits associated with the use of alcohol, cannabis, cocaine, benzodiazepines, and hallucinogens: evidence from a large Brazilian web survey. Revista Brasileira de Psiquiatria. 2015 Mar;37(1):31-9.

11. Kaviani H, Pourahmad M, validation of temperament and character inventory (TCI)

12. in Iranian sample, Normative data, TUMJ.2005;6289-98

13. Shoshtari M, sedigh A, Jalali M. Reliability of Persian version of SCID. Cognitive science. 1381; $1: 10-22$

14. Kloos A, Weller RA, Chan R, Weller EB. Gender differences in adolescent substance abuse. Current psychiatry reports. 2009 Apr 1;11(2):120-6.

15. Kulis S, Marsiglia FF, Nagoshi JL. Gender roles and substance use among Mexican American adolescents: A relationship moderated by acculturation? Substance use \& misuse. 2012 Jan 17;47(3):214-29. 
16. Stephen M. Strakowski, Melissa P. DelBello, David E. Fleck, and Stephan Arndt. The impact of substance abusers on the course of bipolar disorder. Biol Psychiatry2000; 48:477-485.

17. Wu LT, Anthony JC. Tobacco smoking and depressed mood in late childhood and early adolescence. American Journal of Public Health. 1999 Dec;89(12):1837-40.

18. Schneider Jr R, Ottoni GL, Carvalho HW, Elisabetsky E, Lara DR. Temperament and character traits associated with the use of alcohol, cannabis, cocaine, benzodiazepines, and hallucinogens: evidence from a large Brazilian web survey. Revista Brasileira de Psiquiatria. 2015 Mar;37(1):31-9.

19. Milivojevic D, Milovanovic SD, Jovanovic M, Svrakic DM, Svrakic NM, Svrakic SM, Cloninger CR. Temperament and character modify risk of drug addiction and influence choice of drugs. The American journal on addictions. 2012 Sep 1;21(5):462-7.

20. Haro G, Calabrese JR, Larsson C, Shirley ER, Martín E, Leal C, Delgado PL. The relationship of personality traits to substance abuse in patients with bipolar disorder. European Psychiatry. $2007 \mathrm{Jul}$ 31;22(5):305-8.

21. Bardo MT, Donohew RL, Harrington NG. Psychobiology of novelty seeking and drug seeking behavior. Behavioural brain research. 1996 May 31;77(1):23-43.

22. Volkow ND, Fowler JS, Wang GJ, Swanson JM, Telang F. Dopamine in drug abuse and addiction: results of imaging studies and treatment implications. Archives of neurology. 2007 Nov 1;64(11):1575-9.

23. Bidwell LC, Knopik VS, Audrain-McGovern J, Glynn TR, Spillane NS, Ray LA, Riggs NR, Guillot CR, Pang RD, Leventhal AM. Novelty seeking as a phenotypic marker of adolescent substance use. Substance abuse: research and treatment. 2015;9(Suppl 1):1.

24. Flick SN, Roy-Byrne P, Cowley DS, Shores MM, Dunner DL. DSM-III-R Personality Disorders in mood and anxiety disorders clinic: prevalence, comorbidity, and clinic Correlates. J Affective Disorders 1993; 27:71-79

25. Frances R Levin, Grace Hennesa, Bioplar disorder and subsatance abuse.2004;56:73874

26. Strakowski SM, Stoll AL, Tohen M, Faedda GL, Goodwin DC. The Tridimensional Personality Questionnaire as a predictor of six-month outcome in first episode Mania. Psychiatry Research 1992; 48:1-8

27. Osher Y, Cloninger CR, Belmaker RH. TPQ in euthymic manic-depressive patients. J Psychiatry Res 1996; 30(5):353-357

28. Tiffany A.Greenwood, Judith A.Badner, William Byerley, Paul E.Keck, Susan L McElroy , Ronald A Remick ,.Dessa Sadovnick, John R.Kelsoe. Heritability and linkage analysis of personality in bipolar disorder. Journal of affective disorder.2013;151:748-755

29. Julia E, Marquez_Arrico, Silvia Lopez_vera, Gemma Prat, Ana Adam. Temperament and character dimensions in male patients with substance use disorders: Differences relating to psychiatric comorbidity Psychiatry research. 2016; 237:1-8

30. Henry C, Bellvier F, Sorbara F, Tangwongchai S, Lacoste J, Faure-Chaigneau M, Leboyer M. Bipolar sensation seeking is associated with a propensity to abuse rather Than to temperament characteristics. Eur Psychiatry 2001; 16:289-292

31. Shay T. Loftus, Jessica L. Garno, Judith Jaeger, Anil K. Malhotra. Temperament and character dimensions in bipolar I disorder. Journal of psychiatric research2008; 42:1131-1136.

32. Fabiano G nery, John P Hatch,David C Glahn, Mark A. Nicoletti, E Serap Monkul ,Pablo Najt, Manoela Fonseca ,Charles L .brown, C Robert Cloninger, Jair C Soares . Temperament anad character traits in patients with bipolar disorder and associations with comorbid alcoholism or anxiety diorders. Journal of psychiatric research.2008;42:569-57. 